\title{
Synthesis of Germanium/Multi-walled Carbon Nanotube Core-Sheath Structures via Chemical Vapor Deposition
}

\author{
Dali Qian ${ }^{1}$, Mark Crocker ${ }^{1}$, A. Pandurangan ${ }^{1}$, \\ Cedric Morin ${ }^{1}$ and Rodney Andrews ${ }^{1,2}$ \\ ${ }^{1}$ Center for Applied Energy Research, \\ University of Kentucky, Lexington, KY 40511, \\ ${ }^{2}$ Department of Chemical and Materials Engineering, \\ University of Kentucky, Lexington, KY 40506,
}

USA

\section{Introduction}

One-dimensional (1D) nanostructures such as nanotubes, nanowires, and nanobelts have been the focus of much recent attention, owing to the novel electronic and optical properties intrinsically associated with their low dimensionality and the quantum confinement effect. Such 1D nanostructures have potential applications in nanoelectronics, advanced composites, field emission devices, sensors, probes, optics and optoelectronics (Baughman et al., 2002; Agarwal \& Lieber, 2006). Silicon nanowires have been preferentially studied since $\mathrm{Si}$ is of great technological importance in microelectronics (Morales \& Lieber, 1998). Silicon nanowires exhibit significant differences in physical (Cui \& Lieber 2001; Ma, et al., 2003; Sun et al., 2001) and chemical properties (Sun et al., 2003; Chen et al., 2005) from bulk $\mathrm{Si}$, which have been exploited to fabricate nanoelectronic devices such as logic circuits (Huang et al., 2001), field effect transistors (Lieber, 2003), and sensors (Cui et al., 2001). Compared to $\mathrm{Si}, \mathrm{Ge}$ nanostructures are of particular interest, since the exciton Bohr radius of bulk Ge (24.3 nm) (Maeda et al., 1991) is larger than that of Si (4.9 nm) (Cullis et al., 1997), resulting in more prominent quantum confinement effects. Ge also offers the advantage of lower processing temperatures with easier integration into conventional devices. Furthermore, Ge has much higher electron and hole mobility than Si (Sze, 1981), which is especially required when electronic devices are scaled down to the sub- $100 \mathrm{~nm}$ regime.

Several growth methods have been developed for the synthesis of Ge nanowires, including laser ablation (Morales \& Lieber, 1998; Zhang et al., 2000), thermal evaporation (Gu et al., 2001; Nguyen et al., 2005; Sun et al., 2006; Das et al., 2007; Sutter et al., 2008), supercriticalfluid synthesis (Ryan et al., 2003; Polyakov et al., 2006; Ziegler et al., 2004; Erts et al., 2006), liquid-state synthesis (Heath \& LeGoues, 1993; Song et al., 2009), molecular beam epitaxy (Omi \& Ogino, 1997), and chemical vapor deposition (CVD) (Kodambaka et al., 2007; Ryan et al., 2003). CVD has been the most widely employed of these synthesis methods, with the aim of synthesizing Ge nanowires in a controllable way via the selection of suitable Ge 
precursors and catalysts. To date a number of Ge-containing precursors have been used to grow Ge nanowires, including $\mathrm{GeH}_{4}$ (Kamins et al., 2004; Wang \& Dai, 2002; Jin et al., 2006; Kang et al., 2008; Wang \& Dai, 2006), $\mathrm{Ge}_{2} \mathrm{H}_{6}$ (Kodambaka et al., 2007), $\mathrm{Ge}\left(\mathrm{C}_{5} \mathrm{H}_{5}\right)_{2}$ (Mathur et al., 2004; Mathur \& Barth, 2008), $\mathrm{C}_{12} \mathrm{H}_{12} \mathrm{Ge}$ (diphenyl germane) (Ryan et al., 2003; Hanrath \& Korgel, 2002; Polyakov et al., 2006; Ziegler et al., 2004; Erts et al., 2006), Ge-GeO $\mathrm{G}_{2}$ (Yin et al.,

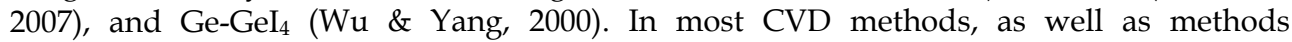
employing thermal evaporation of Ge powders (Gu et al., 2001; Nguyen et al., 2005; Sun et al., 2006; Das et al., 2007; Sutter et al., 2008), Au nanoparticles have been typically selected as the catalyst for Ge nanowire growth via the vapour-liquid-solid (VLS) mechanism (Wagner \& Ellis, 1964) due to the low eutectic temperature of the Ge-Au alloy $\left(360^{\circ} \mathrm{C}\right)$. Other low melting point metals/alloys that have been employed as the catalyst include $\mathrm{Al}$ (Wang et al., 2006), Cu (Yao \& Fan, 2007), Cu-Ni (Kang et al., 2008) and Fe(Ge) (Mathur, et al., 2004). Recently, the vapor-solid-solid (VSS) mechanism (Kamins et al. 2001; Bootsma \& Gassen, 1971) has also been implicated, based on experimental observations that the catalyst state can be either liquid or solid depending on the thermal history, $\mathrm{Ge}_{2} \mathrm{H}_{6}$ pressure, and temperature. The supersaturation of Ge in the alloy catalyst caused by the growth process appears to be essential in stabilizing the liquid below the eutectic temperature; therefore, Ge nanowires can grow by both the VLS and VSS mechanisms, although at different rates (Kodambaka et al., 2007).

Although highly ordered metallic and semiconductor nanowires can be used in electronic devices, in many cases these nanowires are sensitive to oxygen and water vapor, resulting in degradation of the nanodevice performance (Zhang et al., 2007). Consequently, in some cases it is necessary to avoid any contact of these materials with the external environment. This is particularly important for Ge, which forms oxide coatings possessing unfavorable electronic properties. Untreated Ge nanowires are reported to oxidize upon exposure to ambient conditions to form a 1-2 nm thick $\mathrm{GeO}_{2-x}$ shell, which continues to grow to reach a self-limited thickness of $\sim 4 \mathrm{~nm}$ over the course of $\sim 24 \mathrm{~h}$ (Hanrath \& Korgel, 2004). A promising solution to this problem is the coating of metallic or semiconductor nanowires with organic monolayer coatings such as those based on alkanethiols (Wang et al., 2005) or alkyl groups (Hanrath \& Korgel, 2004), or with a protective shell of carbon nanotubes (CNTs) (Sutter \& Sutter, 2006; Dai et al., 1996; Loiseau et al., 2000; Wu \& Yang, 2000) or amorphous carbon (Huang et al., 2005).

Carbon-encapsulated Ge nanowires have previously been prepared using a chemical vapor deposition (CVD) technique (Sutter \& Sutter, 2006). A supported Au catalyst was employed to catalyze the growth of Ge nanowires, which were then dispersed on an amorphous carbon film and annealed, resulting in the encapsulation of the nanowires by well defined, curved graphene sheets. The presence of gold nanoparticles (residual catalyst) on the surface of the nanowires was indicated as being instrumental in initiating graphene sheet formation. Other methods which have been employed for the preparation of $\mathrm{Ge} / \mathrm{C}$ coresheath nanostructures include the arc discharge synthesis of CNTs in the presence of Ge metal (Dai et al., 1996; Loiseau et al., 2000), and the deposition of graphitic coatings on preformed Ge nanowires by their treatment with organic vapors at $700-900{ }^{\circ} \mathrm{C}(\mathrm{Wu} \&$ Yang, 2000).

For practical circuit device fabrication, e.g., for photoresistors (Polyakov et al., 2006), photoluminescence devices (Ryan et al., 2003) and gas sensors (Rajaputra et al., 2008), ordered nanowire arrays are required. To this end, Holmes's research group has employed 
ordered mesoporous aluminosilicate thin films (Ryan et al., 2003; Ziegler et al., 2004) and AAO membranes (Polyakov et al., 2006; Erts et al., 2006) as templates to grow Ge nanowire arrays by the degradation of diphenylgermane $\left(\mathrm{C}_{12} \mathrm{H}_{12} \mathrm{Ge}\right)$ in supercritical $\mathrm{CO}_{2}$. The experimental protocol involved placing the ordered porous films or AAO membranes inside a $25 \mathrm{~mL}$ high-pressure reaction cell with diphenylgermane placed inside an open top quartz glass boat adjacent to the membranes under an inert atmosphere. A typical synthesis at 600 ${ }^{\circ} \mathrm{C}$ under $37.5 \mathrm{MPa}$ for $30 \mathrm{~min}$ resulted in conductive Ge nanowires which filled the template pores (Ziegler et al., 2004).

To meet the demands for practical device fabrication, we have studied the synthesis of Ge nanowires protected through encapsulation in multi-walled carbon nanotubes (MWCNTs) using a simple one-step synthesis method (Pandurangan et al., 2009). In this approach, a CVD method employing neat phenyltrimethylgermane (PTMG, boiling point of b.p. $183{ }^{\circ} \mathrm{C}$ ) was used, the PTMG functioning as both the Ge and C source. Although transition metal catalysts have typically been employed for the synthesis of CNTs, it has recently been shown that semiconductor nanoparticles of $\mathrm{SiC}, \mathrm{Ge}$ and $\mathrm{Si}$ can act as templates for the production of single-walled and double-walled carbon nanotubes during CVD synthesis with ethanol (Takagi et al., 2007). In this study, pure PTMG acts as a precursor for the formation of $\mathrm{Ge}$ nanoparticles which act as templates for the formation of MWCNTencapsulated Ge nanowires. The effect of employing a floating Fe catalyst, using ferrocene as a precursor, has also been investigated. To tailor the derived Ge nanowire diameter and orientation, the use of anodized aluminum oxide (AAO) templates has also been evaluated.

\section{Synthesis of Ge nanowires encapsulated within multiwalled carbon nanotubes}

Previous work in our laboratory (Andrews et al., 1999) and others (Öncel \& Yürüm, 2006) has established chemical vapor deposition (CVD) as an efficient means of preparing multiwalled carbon nanotubes (MWCNTs). In addition to the relatively simple equipment required, the use of CVD enables the process to be readily scaled, such that MWCNTs can be produced in quantities ranging from milligrams to kilograms. Consequently, to prepare MWCNT-encapsulated Ge nanowires, we elected to employ the same basic CVD technique. However, rather than using a floating catalyst such as ferrocene (required to catalyze MWCNT growth) dissolved in a carbon precursor such as xylene, we elected to employ neat PTMG as both the Ge and C source. In effect, PTMG acts as a precursor for the formation of Ge nanoparticles which, in turn, function as templates for the formation of MWCNTencapsulated Ge nanowires (Pandurangan et al., 2009).

The two-zone furnace employed for the CVD preparation was similar to that described previously for the growth of pristine MWCNTs, and consisted of a quartz tube reactor with a flat quartz slide inserted at the reaction zone for additional deposition surface (Andrews et al., 1999). Neat PTMG was injected into the preheat zone of the reactor at a rate of $1 \mathrm{ml} / \mathrm{h}$. After volatilization in the preheat zone $\left(\sim 250{ }^{\circ} \mathrm{C}\right)$, the PTMG was carried into the reaction zone of the furnace, maintained at $800{ }^{\circ} \mathrm{C}$, by a $10 \% \mathrm{H}_{2} / \mathrm{Ar}$ sweep gas. The entire system was maintained at a slight positive pressure $(\sim 0.75 \mathrm{kPa})$ versus atmospheric pressure. Typical CVD runs were of $2 \mathrm{~h}$ duration, after which the material deposited on the quartz slide was collected for analysis. 
Representative scanning electron micrographs of the material prepared at $800{ }^{\circ} \mathrm{C}$ are shown in Fig. 1. These show the sample to consist mainly of nanowires, possessing diameters of less than $500 \mathrm{~nm}$ (see Fig. 1b). The nanowires appear smooth, with little evidence of metal cluster formation. Furthermore, from Fig. 1 and other micrographs, it is apparent that the as-synthesized nanowires are largely free from amorphous carbon and possess large aspect ratios, the typical length being in the order of $10 \mu \mathrm{m}$. In contrast, at $700{ }^{\circ} \mathrm{C}$ decomposition of the precursor appears to be incomplete; consequently, only a few short wires are formed. Increase of the temperature above $800{ }^{\circ} \mathrm{C}$ results in the formation of amorphous carbon, with Ge nanoparticle formation being favored over the formation of nanowires.
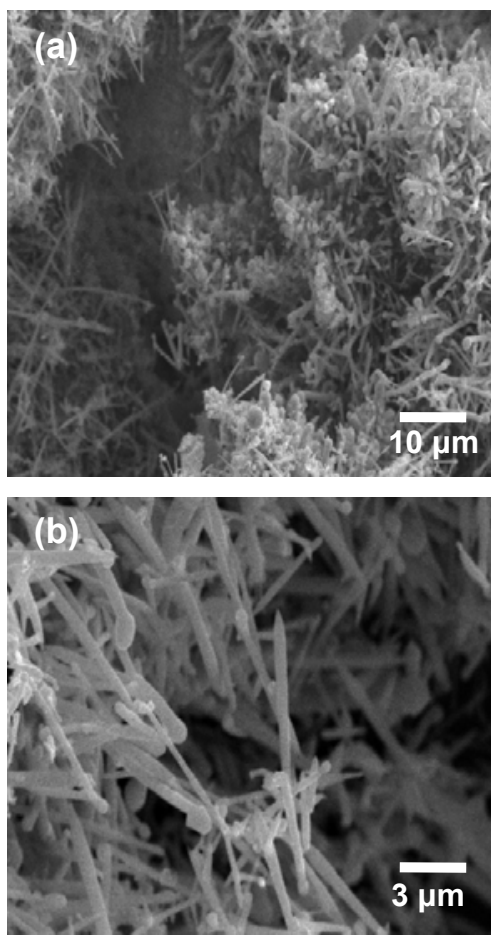

Fig. 1. (a) Typical SEM image of Ge-filled MWCNTs synthesized at $800^{\circ} \mathrm{C}$, and (b) higher magnification image showing MWCNT tips.

As revealed by TEM, the product obtained at $800{ }^{\circ} \mathrm{C}$ (hereafter denoted as Ge@MWCNT/800) consists of crystalline Ge nanowires, encapsulated in a thin MWCNT sheath. Typical TEM images at low magnification (see Fig. 2a) reveal a pin-like morphology. TEM images at higher magnification (Fig. 2b-d) show that the Ge nanowires consist of well crystallized Ge cores which are completely encapsulated by the sheath-like MWCNTs possessing a thickness of 5-10 nm. Ge incorporation within the graphene sheets of the MWCNTs is not observed according to EDS analysis under STEM mode. Quantitative EDS analysis of the tube cores indicates a composition of 95\% Ge and 5\% C (atom \%). Given the existence of 5-10 $\mathrm{nm}$ thick of graphene (C) layers covering the Ge core at the analytical probe position, it can be concluded that the core consists of pure Ge, as supported by HRTEM 
observations that show clear fringes corresponding to single crystal Ge (see Fig. 2c, 2d). Furthermore, EDS analysis confirmed that the near spherical heads of the nanowires consist of over 97 atom \% Ge (the balance being C).

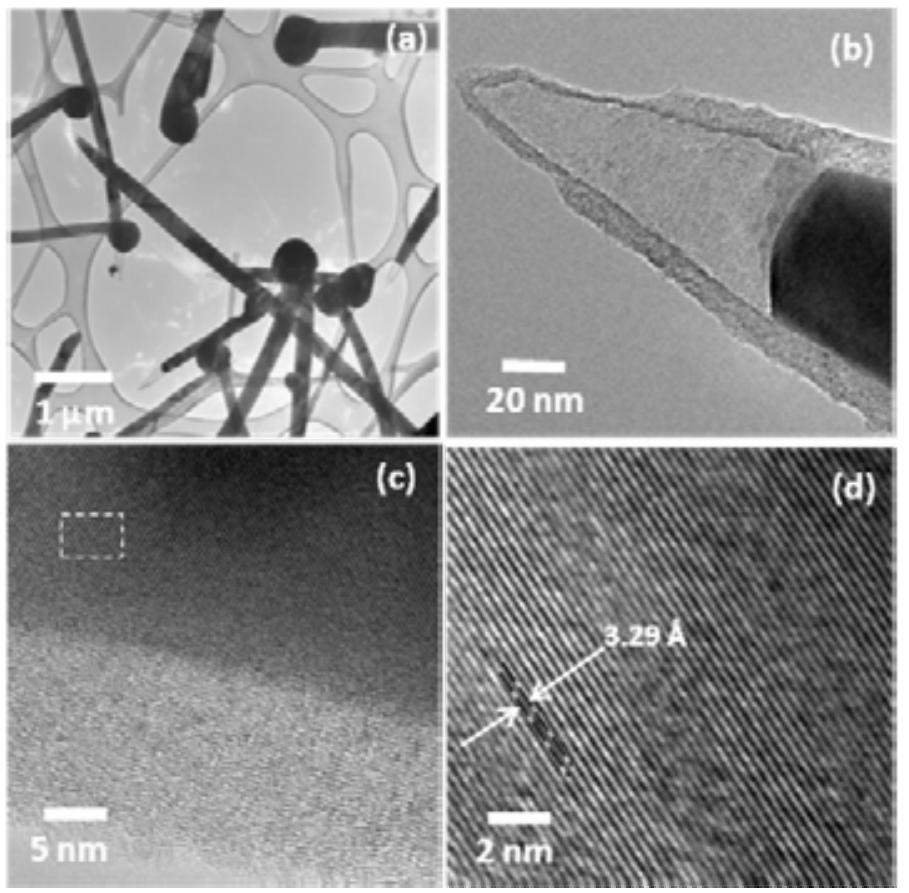

Fig. 2. (a) typical TEM images of Ge@MWCNT/800 at low magnification; (b) and (c) high magnification image showing Ge nanowire and MWCNT sheath; (d) higher magnification view of boxed area in (c) showing single crystal Ge.

Powder X-ray diffraction data confirm the crystalline nature of the nanowires (Fig. 3a). The positions of the observed diffraction peaks $\left(2 \theta=27.43,45.45,53.83,66.13,73.11,83.79^{\circ}\right)$ are in good agreement with literature values (Miikin, 1961) for the crystalline face centered cubic phase of Ge with lattice parameter $a=5.660 \AA$. Furthermore, the neighbor interlayer spacing indexed in HRTEM images (see Fig. $2 \mathrm{~d}$ ) is approximately $3.29 \AA$, which is very close to the calculated distance between neighboring (111) planes of $3.27 \AA$. Thus, the as-produced Ge@MWCNT/800 consists primarily of FCC Ge.

As shown in Fig. 3b, the X-ray photoelectron spectrum of Ge@MWCNT/800 contains two Ge 3d photoelectron lines. The signal corresponding to a binding energy of $29.7 \mathrm{eV}$ can be assigned to $\mathrm{Ge}$ metal, albeit that it is slightly shifted $(\sim 0.3 \mathrm{eV})$ compared to $3 \mathrm{~d}$ binding energies typically observed for bulk $\mathrm{Ge}$. The other signal at $32.5 \mathrm{eV}$ is characteristic of $\mathrm{GeO}_{2}$. Deconvolution of the signals and integration indicates a $\mathrm{Ge}(0) \mathrm{Ge}(\mathrm{IV})$ atomic ratio of 78:22, suggesting that the Ge nanowires are largely, although not completely, protected from oxidation. Additionally, it is likely that amorphous, partially oxidized Ge is present, which contributes to the $\mathrm{GeO}_{2}$ signal. While SEM analysis of Ge@MWCNT/800 suggests that nanowires constitute at least $80 \%$ of the sample, the presence of irregularly shaped Ge particles can be observed in some SEM images (as shown in Fig. $5 \mathrm{c}$ below). 

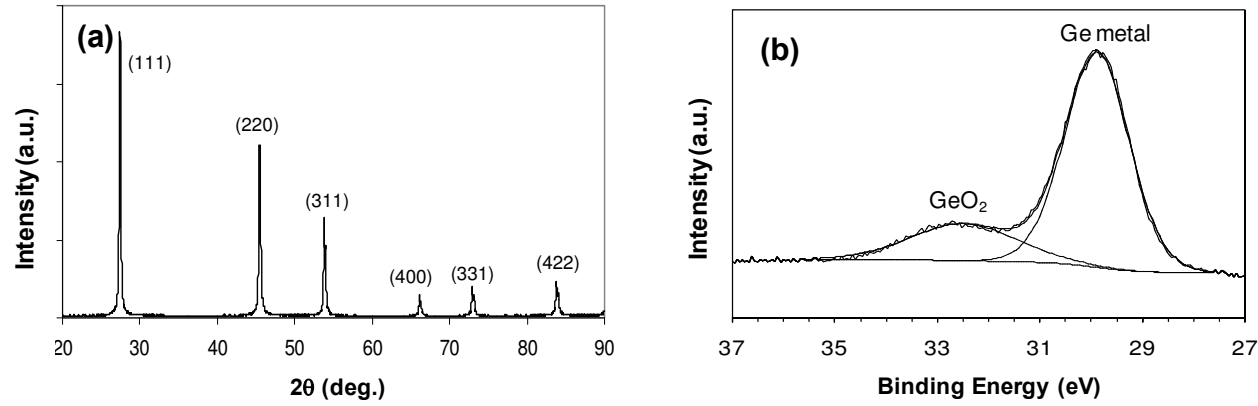

Fig. 3. Characterization of Ge@MWCNT/800: (a) powder XRD pattern and (b) XPS spectrum.

The results of thermogravimetric analysis performed on Ge@MWCNT/800 in air are shown in Fig. 4a. Noteworthy is the observation that a pronounced increase in sample weight commences at around $550{ }^{\circ} \mathrm{C}$, consistent with the oxidation of $\mathrm{Ge}$ to $\mathrm{GeO}_{2}$. This temperature corresponds to the initiation of MWCNT combustion (Bom et al., 2002), suggesting that Ge oxidation proceeds as the nanowires' outer carbon shells are oxidized and the Ge cores are exposed. Allowing for the initial carbon content of $3 \mathrm{wt} . \%$ in the sample (by elemental analysis), and assuming that all of the Ge present is oxidized to $\mathrm{GeO}_{2}$, the observed gain in sample weight $(37 \%)$ corresponds to an initial molar $\mathrm{Ge}: \mathrm{GeO}_{2}$ ratio of $86: 14$ (in reasonable agreement with the value determined by XPS). As shown in Fig. $4 \mathrm{~b}$, differential scanning calorimetry (DSC) performed under $\mathrm{N}_{2}$ gave a melting point of $934{ }^{\circ} \mathrm{C}$ for the Ge nanowires.
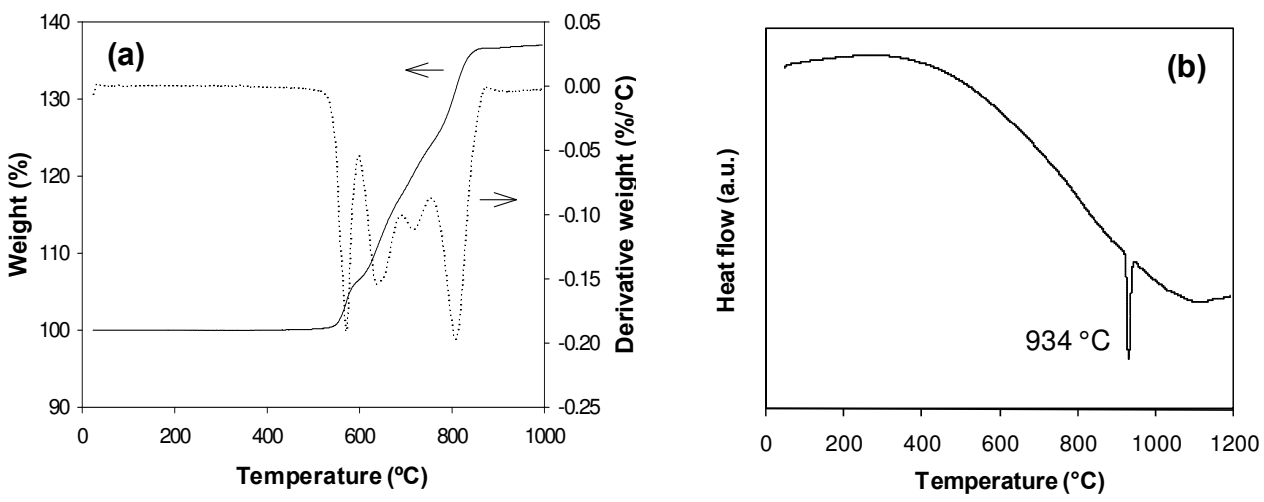

Fig. 4. Characterization of Ge@MWCNT/800: (a) thermogravimetric analysis in air and (b) differential scanning calorimetry in $\mathrm{N}_{2}\left(10^{\circ} \mathrm{C} / \mathrm{min}\right.$ heating rate used in both cases).

In the absence of an external carbon source, the carbon constituting the MWCNTs derives from the phenyltrimethylgermane precursor. In principle, an atomic $\mathrm{Ge}: \mathrm{C}$ ratio of 1:9 is feasible in the product if decomposition of the precursor proceeds according to: $\mathrm{C}_{6} \mathrm{H}_{5} \mathrm{Ge}\left(\mathrm{CH}_{3}\right)_{3} \rightarrow \mathrm{Ge}+9 \mathrm{C}+7 \mathrm{H}_{2}$. In fact, elemental analysis of the product typically showed a Ge:C ratio of $c a$. 5:1, indicating that most of the carbon is lost in the form of volatile species (methane and ethene). 

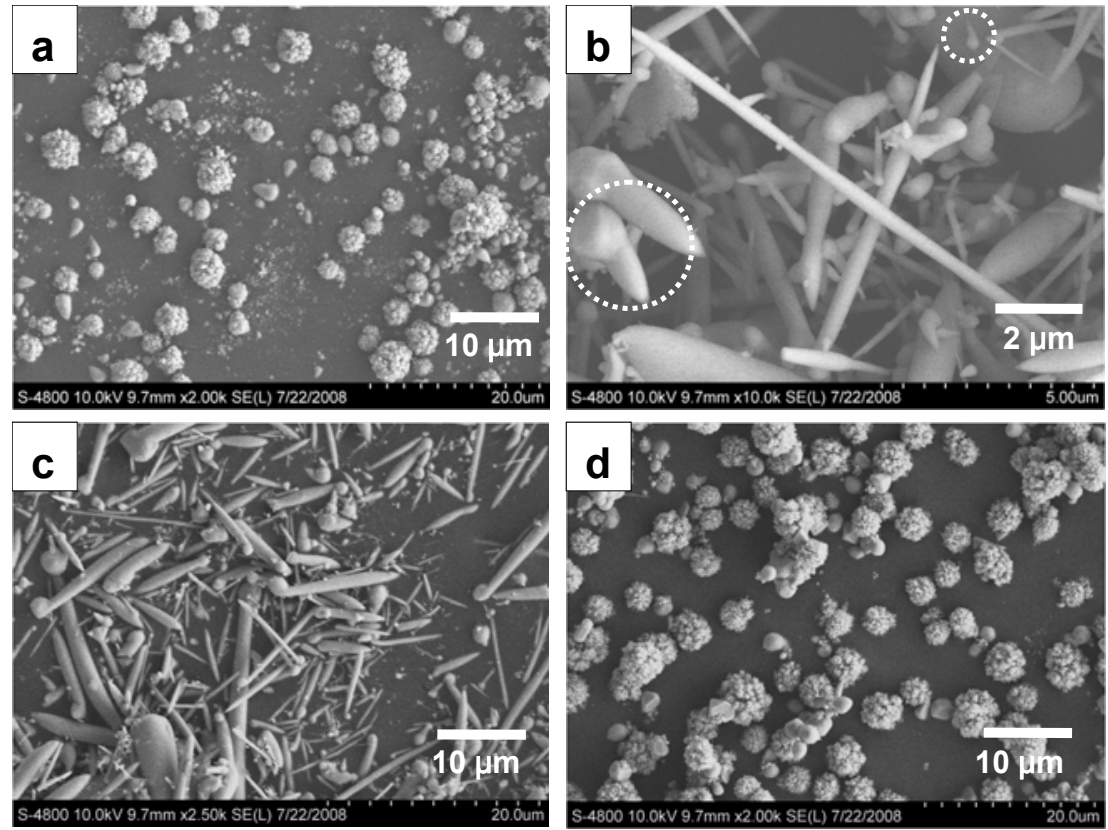

Fig. 5. (a)-(d) SEM images of CVD product obtained using neat PTMG: (a) 3", (b) 4", (c) 5" and (d) 7" from inlet; the circled regions in image b show Ge particles at an early stage of nanowire formation.

Insight into the factors controlling nanowire formation is provided by the results of CVD experiments in which the deposited solid was sampled from quartz slides placed at fixed distances from the inlet, i.e., along the length of the tube reactor. The reaction zone was again held at $800{ }^{\circ} \mathrm{C}$. SEM images of these materials are shown in Figs. 5 and 6. Images 5a$5 \mathrm{~d}$ correspond to a CVD run performed using neat PTMG as the precursor, while images 6a$6 \mathrm{~d}$ correspond to the product obtained using PTMG diluted to $50 \mathrm{wt} \%$ with xylene. For both runs, light deposits of mainly amorphous Ge particles were obtained closest to the inlet. For the run using neat PTMG, nanowires could be found in a localized region of the reactor, between $4^{\prime \prime}$ and 5" from the inlet. Further away from the inlet, Ge particles were obtained (Fig. 5d). Evidently, while carbon is available beginning at 4 " from the inlet from cracking of the PTMG, the partial pressure of carbon in the atmosphere is insufficient to produce Ge-filled nanotubes along the entire length of the reactor. In contrast, when the PTMG/xylene mixture was used, not only was the total yield of Ge-filled nanotubes increased (estimated at $>50 \%$ based on Ge), Ge-filled nanotubes were observed in the entire region $4 "-7$ " from the inlet. Furthermore, the dimensions of the filled nanotubes were rather uniform, with diameters in the 200-300 $\mathrm{nm}$ range and lengths of 6-10 $\mu \mathrm{m}$. These results suggest that the form of the germanium deposit obtained is regulated by the partial pressure of carbon in the atmosphere.

For the runs performed with both neat PTMG and PTMG/xylene, structures could be observed which appear to correspond to the early stages of nanotube/nanowire growth. Examples of this are shown in the circled regions of Fig. 5b. CNT growth evidently occurs 

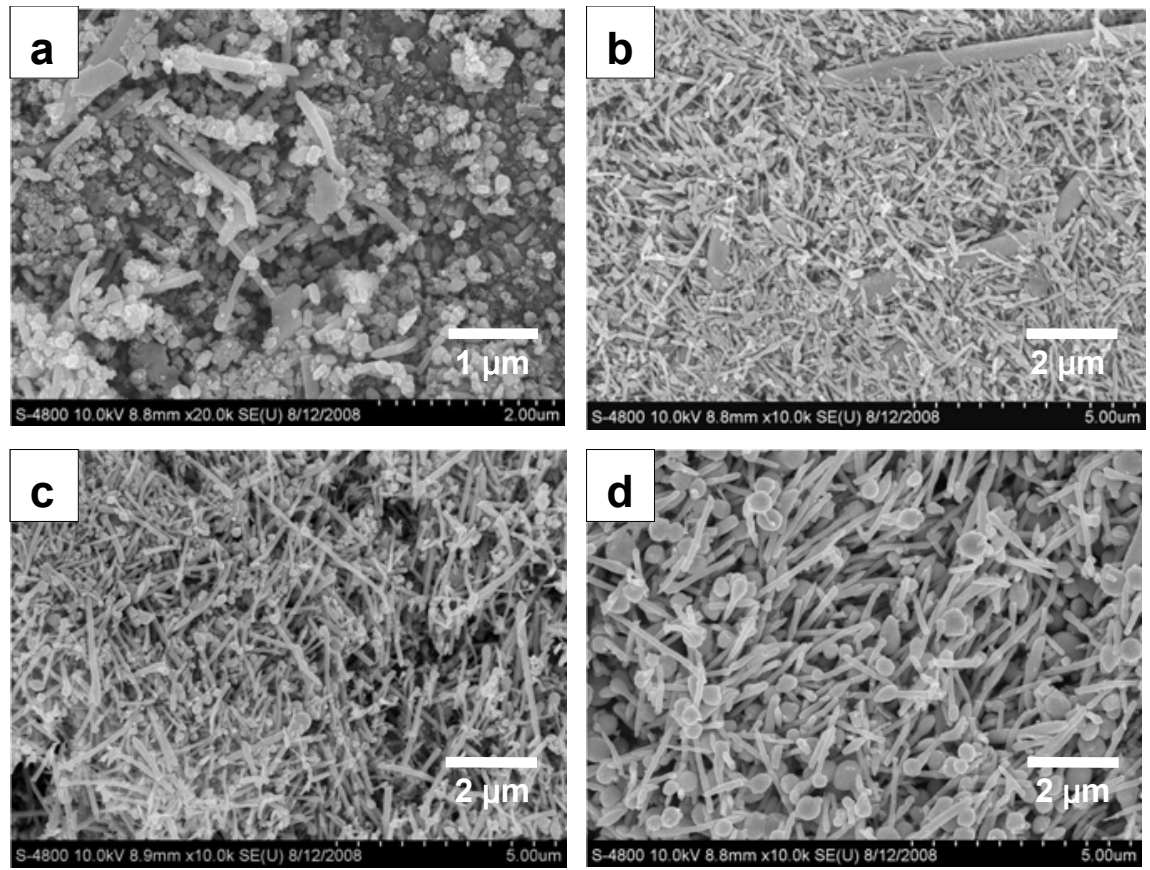

Fig. 6. SEM images of CVD product obtained using $50 \mathrm{wt} \%$ PTMG in xylene: (a) 3", (b) 4", (c) 5" and (d) 7" from inlet.

from the Ge particle (root growth mechanism) and appears to carry Ge as a nanowire away from the initial particle. Presumably, this synthesis mode is the result of wetting at the interface of the Ge and the growing carbon nanotube. This is illustrated in Fig. 2c, which shows the high degree of association between the carbon sheath and the Ge nanowire. It should be noted that the synthesis temperature used $\left(800^{\circ} \mathrm{C}\right)$ was more than $100{ }^{\circ} \mathrm{C}$ lower than the melting point of Ge. As shown in Fig. 4b, a m.p. of $934^{\circ} \mathrm{C}$ was measured for the Ge nanowires. While this is only slightly lower than the melting point for bulk Ge $\left(938^{\circ} \mathrm{C}\right)$, it has been reported that smaller nanoscale metal structures can exhibit much greater melting point depression (Buffat \& Borel, 1976; Couchman \& Jesser, 1977). Hence, melting point depression can be expected during the initial stages of nanowire growth. This effect, together with possible capillary action (Dujardin et al., 1994), can explain the apparently low Ge viscosity and the tendency for CNT filling by Ge.

Finally, it is worth noting that initial attempts to prepare MWCNT-encapsulated Si, Sn or Bi nanowires using this approach have proved unsuccessful. In the case of silicon, this can be attributed to its high melting point $\left(1410^{\circ} \mathrm{C}\right)$, such that any Si nanoparticles formed will be solid at the synthesis temperature. In the case of $\mathrm{Sn}$ and $\mathrm{Bi}$, the melting points are much lower (232 and $271^{\circ} \mathrm{C}$, respectively). In this case, the observation of metallic deposits in the pre-heat zone is consistent with the relatively low decomposition temperatures of the organometallic precursors used $\left(\mathrm{Sn}\left(\mathrm{C}_{6} \mathrm{H}_{5}\right)\left(\mathrm{CH}_{3}\right)_{3}\right.$ and $\left.\mathrm{Bi}\left(\mathrm{C}_{6} \mathrm{H}_{5}\right)_{3}\right)$, i.e., deposition occurs in a region where the temperature is too low for carbon nanotube formation to occur. Consequently the need for precursors which are less thermally labile is indicated. 


\section{Synthesis of Ge-Fe nanowires encapsulated by multiwalled carbon nanotubes}

Recent work has shown that the properties of nanotubes formed by assembly of metal encapsulated silicon and germanium clusters can be tailored by a suitable choice of metal atoms (Pokropivnyi, 2001). Fe-doped ferromagnetic Si nanotubes and Mn-doped Si nanotubes with nearly degenerate ferromagnetic and antiferromagnetic states have been obtained with high local magnetic moments (Singh et al., 2004), making them attractive for nanomagnetic and spintronic devices. Although Mn doping in bulk Ge has found to give rise to weak ferromagnetic behavior (Park et al., 2002; Cho et al., 2002), in low dimensional systems such as nanowires the magnetic behavior could be very rich depending upon the nanostructure and doping of metals. From this it follows that the synthesis of MWCNTencapsulated Ge-Fe nanowires is of interest.

To prepare Ge-Fe nanowires, the same one-step CVD process was used as successfully employed for the growth of encapsulated Ge nanowires, employing PTMG, pyridine and ferrocene as precursor materials. Ferrocene (b.p. $249{ }^{\circ} \mathrm{C}$ ) has been shown to be an excellent precursor for producing metallic iron catalyst particles which can seed carbon nanotube growth. Pyridine was used as the solvent and additionally functions as the primary carbon source. In a typical run $1.15 \mathrm{~g}$ of ferrocene was dissolved in $10 \mathrm{~g}$ pyridine, to which $1.0 \mathrm{~g}$ of
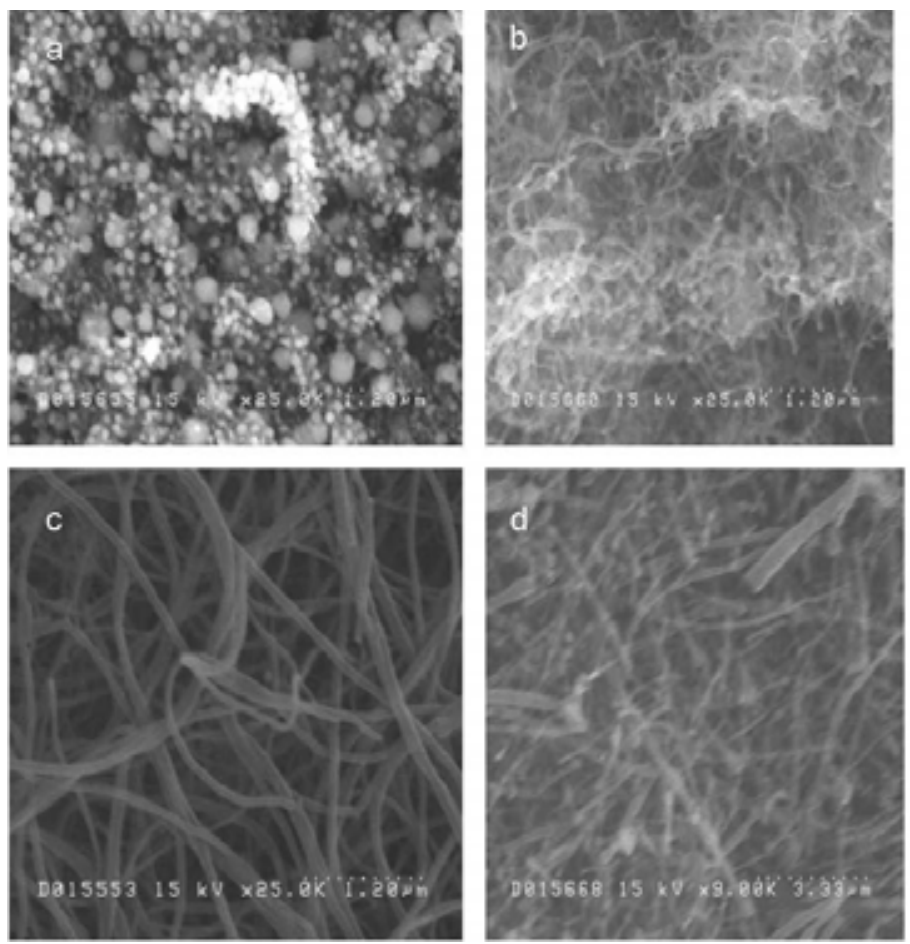

Fig. 7. Typical SEM images of Ge-Fe filled MWCNTs produced by CVD at (a) $700{ }^{\circ} \mathrm{C}$, (b) 800 ${ }^{\circ} \mathrm{C}$, (c) $900^{\circ} \mathrm{C}$, (d) $1000^{\circ} \mathrm{C}$ showing nanotube formation. The micrometer-sized particles in (a) are Ge-Fe clusters as confirmed by EDS mapping. 
PTMG was added. The homogeneous solution was injected into the preheat zone of the reactor $(\sim 250 \circ \mathrm{C})$ at an addition rate of $1 \mathrm{~mL} / \mathrm{h}$ and the resulting vapor was swept into the reaction zone of the furnace by a $10 \% \mathrm{H}_{2}$ / Ar carrier gas.

After a typical CVD run of $2 \mathrm{~h}$ duration, the black deposit obtained was recovered and analyzed by SEM. Figure 7a-7d shows SEM images of the product formed at temperatures varying between 700 and $1000{ }^{\circ} \mathrm{C}$. From Figure $7 \mathrm{~b}$ and other micrographs it is apparent that the nanotube bundles obtained at $800{ }^{\circ} \mathrm{C}$ are free from other carbonaceous materials and possess large aspect ratios, typical nanotube length being in the order of $10 \mu \mathrm{m}$. In contrast, at $700{ }^{\circ} \mathrm{C}$ only a few short MWCNTs are formed (Figure 7a). The majority of the carbon present is amorphous in form, while the metals are observed as particles which are agglomerated on the surface of the carbon. At $800{ }^{\circ} \mathrm{C}$, carbon nanotube production improves significantly, while there is an absence of metal particles. As for Ge@MWCNTS, these findings suggest that the growth kinetics of the MWCNTs at these different temperatures significantly impact the form of the deposited metals. Further increase of the temperature results in decreased MWCNT purity and increased amounts of pyrolytic forms of carbon.

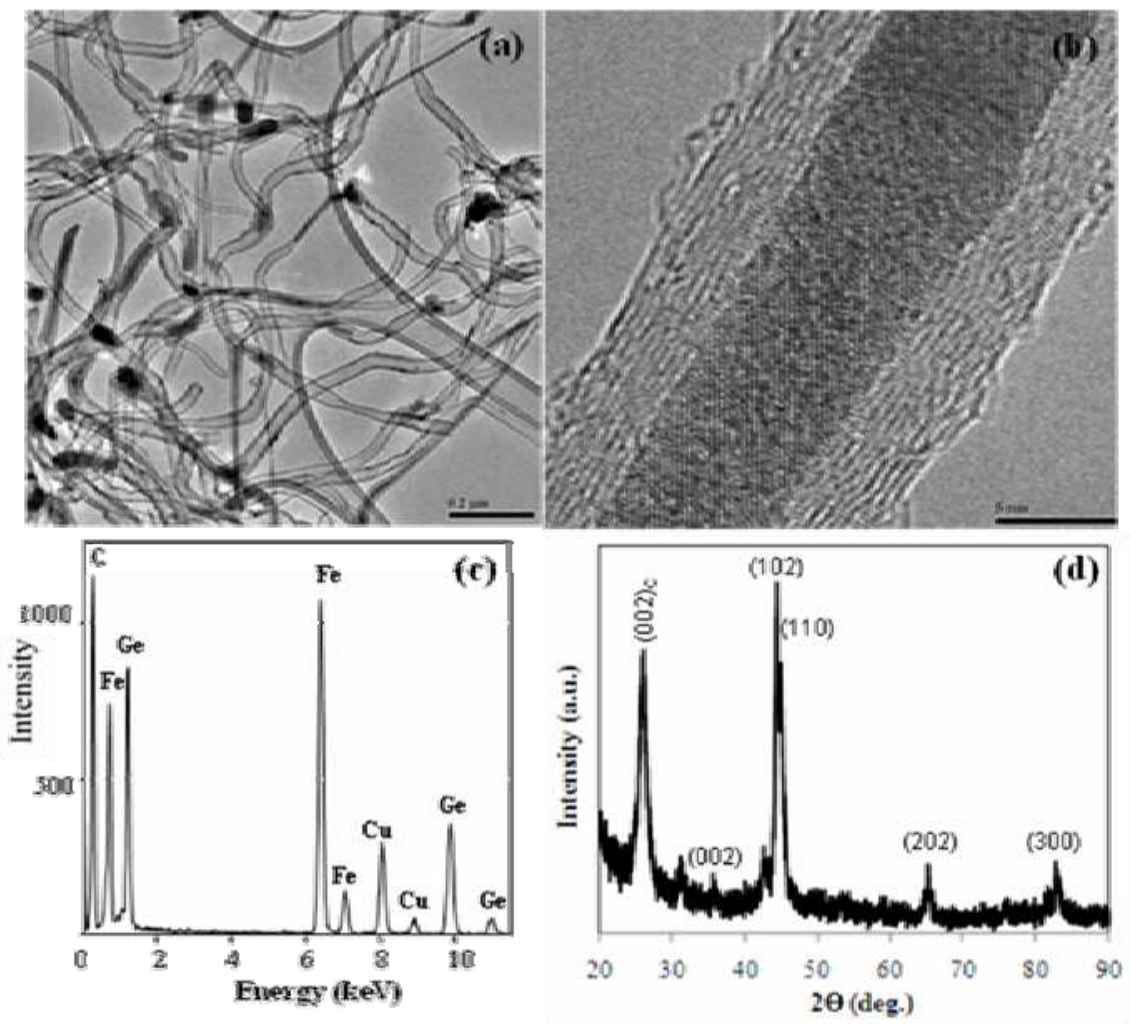

Fig. 8. (a) Low magnification TEM image of Ge-Fe nanowires encapsulated by MWCNTs (produced by CVD at $800{ }^{\circ}$ C); (b) HRTEM image of isolated Ge-Fe filled MWCNT; (c) EDS spectrum of the Ge-Fe core in (b); (d) XRD of bulk Ge-Fe filled MWCNT sample indexed as $\mathrm{Fe}_{1.67} \mathrm{Ge}$; the additional diffraction peak at $26.0^{\circ}$ corresponds to the carbon (002) reflection. 
As revealed by TEM, the CVD-derived material prepared at $800{ }^{\circ} \mathrm{C}$ (Figure 8 ) consists of pure MWCNTs possessing cores composed of a Ge-Fe alloy. As shown in Figures 8a and 8b, the Ge-Fe nanowires consist of a uniform single crystal core with the exception of an enlarged head and tail portion, and are completely encapsulated by the MWCNTs. Figure $8 \mathrm{~b}$ shows a high magnification view of a completely filled MWCNT. From this and other images it is apparent that these nanowires are indeed crystalline and without an amorphous coating of any kind, as is sometimes observed for metallic nanowires (Morales \& Lieber, 1998). According to TEM, the outer diameter of the Fe-Ge filled MWCNTs lies in the 20-70 $\mathrm{nm}$ range, with the diameter of the Ge-Fe cores falling in the range 5-15 $\mathrm{nm}$. Electron energy loss spectroscopy (EELS) analysis under STEM mode shows a sharp C-K edge at $284 \mathrm{eV}$, indicating that the carbon atoms are in the $\mathrm{sp}^{2}$-hybridized state. The EDS spectrum obtained from the MWCNT-sheathed nanowires show the presence of $\mathrm{Ge}, \mathrm{Fe}$ and $\mathrm{C}$ (Figure 8c), while XRD (Figure 8d) shows diffraction peaks which are close to those characteristic for the phase $\mathrm{Fe}_{1.67} \mathrm{Ge}$ (PDF\# 00-017-0232).

Examination of Ge binary phase diagrams shows that the Ge-rich region of the $\mathrm{Ge}-\mathrm{Fe}$ diagram (Mathur et al., 2004) is similar to that of the Si-Fe diagram (Morales \& Lieber, 1998; Moffatt, 1976); above $838{ }^{\circ} \mathrm{C}$ the phases are $\mathrm{FeGe}_{\mathrm{x}(\mathrm{l})}+\mathrm{Ge}_{(\mathrm{s})}$, and below this temperature they are $\beta-\mathrm{FeGe}_{2(\mathrm{~s})}+\mathrm{Ge}_{(\mathrm{s})}$. The mechanism of $\mathrm{Ge}-\mathrm{Fe}$ nanowire formation is therefore likely to follow that proposed above for the growth of $\mathrm{Ge}$ nanowires, i.e., involving $\mathrm{Ge}-\mathrm{Fe}$ nanoparticle formation, followed by carbon nanotube growth and nanotube filling by the mobile Ge-Fe phase. In comparison with the Ge nanowire synthesis, the elemental C:metal ratio used in the Ge-Fe nanowire synthesis is much higher, i.e., $\mathrm{C}:(\mathrm{Ge}+\mathrm{Fe})=112$, as opposed to the C:Ge ratio of 24 used in the optimized Ge nanowire synthesis (employing $50 \mathrm{wt} \%$ PTMG in xylene). Consequently, there appears to be insufficient Ge-Fe alloy to completely fill the nanotubes, as evidenced by the TEM image in Fig. 8a. Finally, we note that these results contrast with MWCNTs grown using a simple pyridine-ferrocene feedstock via the same floating catalyst CVD method (Qian et al., 2003). In the latter case, conical $\mathrm{Fe}_{3} \mathrm{C}$ catalyst particles are observed in the product, located at each nanotube root (being consistent with a typical root growth model), without any filling of the tube cores by Fe. This supports the idea that the active catalyst in the Ge-Fe system is indeed a Ge-Fe alloy, rather than an iron carbide type catalyst.

\section{Growth of MWCNT-encapsulated Ge nanowires with uniform diameters}

In previous work, vertically aligned carbon nanotube arrays have been grown in the pores of AAO templates using a CVD method similar to the general method described for the synthesis of MWCNTs (Andrews et al., 1999), with the exception that pure xylene was used as the hydrocarbon source without any ferrocene catalyst precursor in the feed (Rajaputra et al., 2008). The resulting aligned MWCNT arrays have been used to fabricate gas sensors (Rajaputra et al., 2008); by monitoring the electrical resistance response, low concentrations of $\mathrm{NH}_{3}$ and $\mathrm{NO}_{2}$ can be detected by these arrays.

In this study, porous AAO templates were fabricated by a two-step anodization process of high purity aluminium tape in a $0.3 \mathrm{M}$ oxalic acid medium as reported earlier (Rajaputra et al., 2008). By selecting suitable electrochemistry parameters, AAO membranes with uniform pore size of $\sim 45 \mathrm{~nm}$ and thickness of $50 \mu \mathrm{m}$ were prepared. Several pieces of these AAO templates were placed on a quartz plate that was inserted in a quartz tube (CVD reactor) at $800{ }^{\circ} \mathrm{C}$, while undiluted PTMG was fed into reactor at a rate of $1 \mathrm{ml} / \mathrm{h}$ for $2 \mathrm{~h}$. After the 
experiment, the color of the AAO templates had changed to black, indicating the presence of deposits. Low magnification SEM shows that nanowires were deposited on the whole top surface of the AAO template (Figure 9a). HRSEM observations reveal that these nanowires have the same shape and length $(10-20 \mu \mathrm{m})$ as those grown on flat quartz slides, but have much smaller, uniform outer diameters of less than $100 \mathrm{~nm}$ (Figure 9c). According to SEM, the AAO template surface is coated with an amorphous-like layer, on top of which $\mathrm{Ge}$ nanowires have been deposited. After intentionally removing this surface coating with a blade, the AAO internal surface can be observed and it is apparent that some of the pores have been filled with nanowires (with closed cap ends, as indicated by the arrows in Figure 9d) or nanotubes (with open tube cores, as indicated by the circles in Figure 9d).
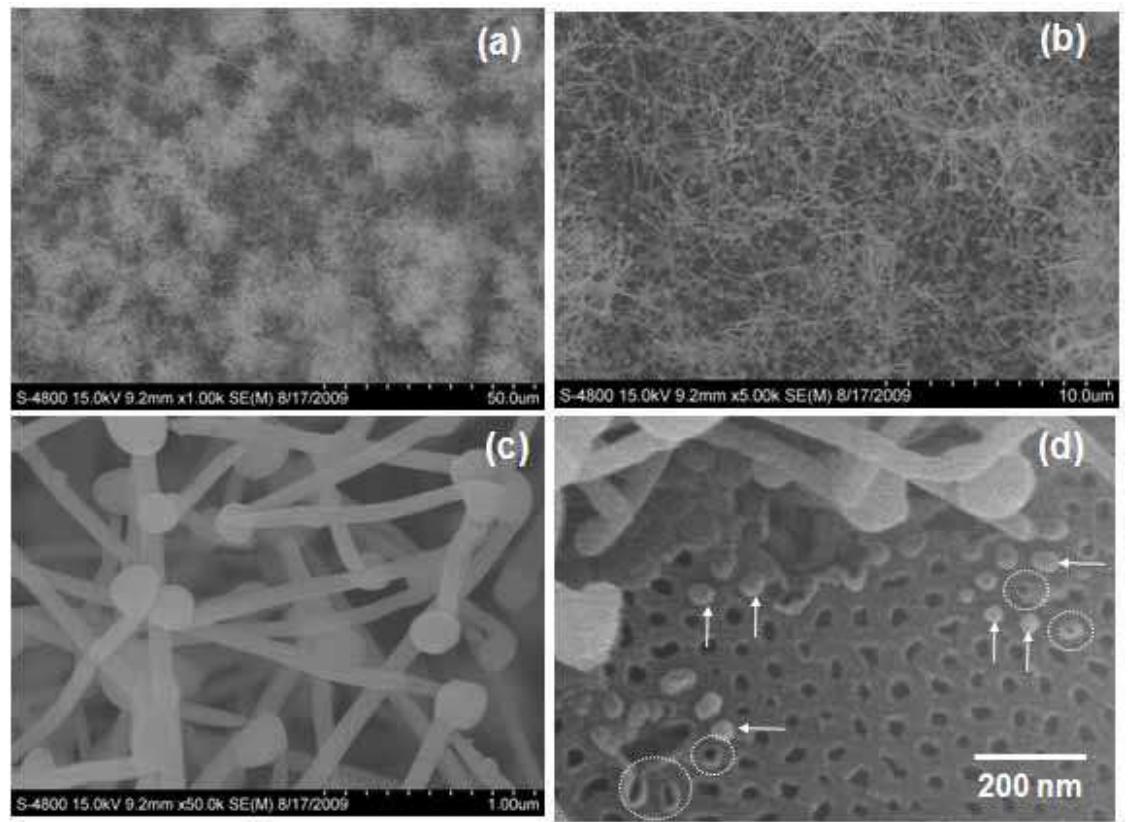

Fig. 9. Typical SEM images of nanowires by CVD of PTMG at $800^{\circ} \mathrm{C}$; deposited on AAO template surface $(\mathrm{a}, \mathrm{b}$ and $\mathrm{c})$; partly deposited within AAO channels $(\mathrm{d})$.

From the cross-sectional view, it is clear that nanowires and nanotubes have grown within the AAO channels, although not along their whole length (Figure 10a and 10b). Energy dispersive spectra contain obvious Ge and C peaks (Figure 10c and 10d), consistent with the presence of MWCNT-encapsulated Ge nanowires. The $\mathrm{Al}$ and $\mathrm{O}$ peaks in the spectra derive from the AAO template, while Au derives from the SEM sample coating (applied to improve the image quality). These Ge@MWCNT nanowires present within the AAO channels have uniform outer diameter, close to the original AAO pore size of $\sim 45 \mathrm{~nm}$.

Efforts to dissolve the AAO template using $\mathrm{H}_{3} \mathrm{PO}_{4}$ or $\mathrm{KOH}$, as done previously for MWCNT/AAO arrays produced from the pyrolysis of xylene (Rajaputra et al., 2008), proved unsatisfactory. The amorphous-like coating covering the AAO surface after CVD may be responsible for slowing the acid dissolution process, which in turn suggests that reactions between the $\mathrm{Ge}$ clusters and $\mathrm{Al}(\mathrm{O})$ surface may have taken place during the $\mathrm{CVD}$ 
process. In this context it is pertinent to note that $\mathrm{Al}$ can catalyze $\mathrm{Si}$ nanowire growth via a vapor-solid-solid (VSS) rather than a VLS mechanism (Wang, et al., 2006). Hence, a similar process, involving a $\mathrm{Ge}-\mathrm{Al}(\mathrm{O})$ phase, may be responsible for the growth of the amorphouslike coating. It is clear, however, that during the CVD process Ge clusters, formed from the PTMG, deposited on both the AAO top surface and the internal channels and catalyzed MWCNT nucleation and growth with incorporation of the Ge as nanowires.
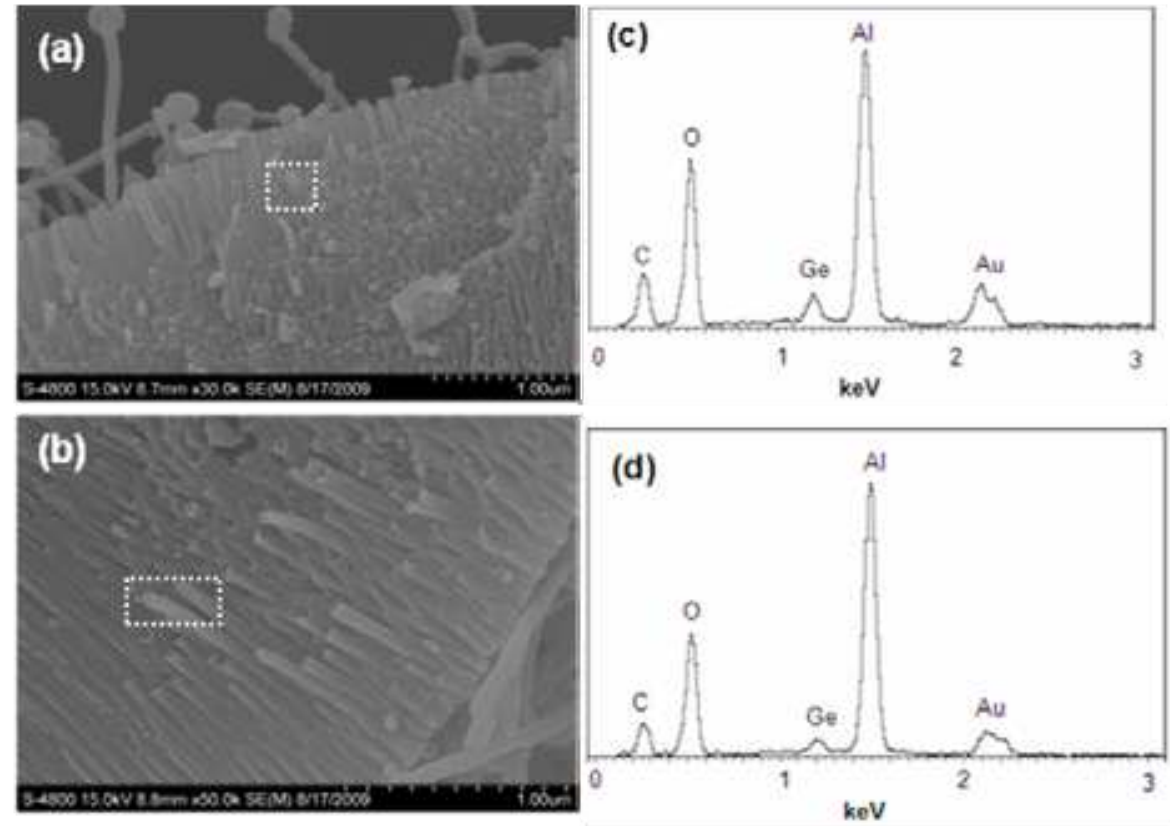

Fig. 10. Typical SEM images of Ge nanowires deposited within AAO channels after CVD of PTMG at $800^{\circ} \mathrm{C}$ ( $\mathrm{a}$ and $\mathrm{b}$ ), and EDS collected from respective boxed regions ( $\mathrm{c}$ and $\mathrm{d}$ ).

\section{Concluding remarks}

CVD using a floating Ge catalyst represents a simple method for the preparation of carbonencapsulated Ge nanowires. The process temperature and the partial pressure of carbon in the reactor are indicated as being critical factors for successful nanowire growth. By optimization of appropriate CVD parameters, such as the C:Ge ratio, reaction time and temperature, nanowires can be reproducibly synthesized with dimensions of 200-300 $\mathrm{nm}$ in diameter and 6-10 $\mu \mathrm{m}$ in length. Furthermore, by using thin AAO plates (i.e., 10-20 $\mu \mathrm{m}$ ) as a template, the growth of MWCNT-encapsulated Ge nanowires with controllable diameter and orientation within AAO can be realized. Although there is a tendency for amorphous deposits to cover the AAO template, the coating can be mechanically removed by polishing to expose MWCNT-encapsulated Ge nanowire arrays which protrude out of the AAO matrix. Past work suggests that it should be possible to exploit these arrays to fabricate gas sensors and optoelectronic devices (Baughman et al., 2002; Agarwal \& Lieber, 2006; Polyakov et al., 2006; Erts et al., 2006). 


\section{Acknowledgement}

The authors would like to thank Drs. S. Rajaputra, R. Mangu and V.P. Singh for kindly supplying high quality AAO templates for this study. This work was supported in part by the Department of Science and Technology, Ministry of Science and Technology, Govt. of India, under young scientist programme award no. SR/BY/C-11/05. A.P. thanks the DST for the award of a BOYSCAST fellowship.

\section{References}

Agarwal, R. \& Lieber, C.M. (2006). Semiconductor nanowires: optics and optoelectronics. Appl. Phys. A, 85, 209-15.

Andrews, R.; Jacques, D.; Rao, A.M.; Derbyshire, F.; Qian, D.; Fan, X.; Dickey, E.C. \& Chen J. (1999). Continuous production of aligned carbon nanotubes: a step closer to commercial realization. Chem. Phys. Lett., 303, 467-74.

Baughman, R.H.; Zakhidov, A.A. \& de Heer, W.A. (2002). Carbon nanotubes - the route toward applications. Science, 297, 787-92.

Bom, D.; Andrews, R.; Jacques, D.; Anthony, J.; Chen, B.; Meier, M.S. \& Selegue, J.P. (2002). Thermogravimetric analysis of the oxidation of multiwalled carbon nanotubes: evidence for the role of defect sites in carbon nanotube chemistry. Nano. Lett., 2, 615-9.

Bootsma, G.A. \& Gassen, H.J. (1971). A quantitative study on the growth of silicon whiskers from silane and germanium whiskers from germane. d Cryst. Growth, 10, 223-34.

Buffat, Ph. \& Borel, J.-P. (1976). Size effect on the melting temperature of gold particles. Phys Rev A, 13, 2287-98.

Chen, W.W.; Sun, X.H.; Wang, S.D.; Lee, S.T. \& Teo, B.K. (2005). Etching behavior of silicon nanowires with $\mathrm{HF}$ and $\mathrm{NH}_{4} \mathrm{~F}$ and surface characterization by attenuated total reflection fourier transform infrared spectroscopy: similarities and differences between one-dimensional and two-dimensional silicon surfaces. I Phys. Chem. B, 109, 10871-9.

Cho, S.; Choi, S.; Hong, S.C.; Kim, Y.; Ketterson, J.B.; Kim, B.-J.; Kim, Y.C.; Jung, J.-H. (2002). Ferromagnetism in Mn-doped Ge. Phys. Rev. B 66, 033303.

Coleman, N.R.B.; Morris, M.A.; Spalding, T.R. \& Holmes, J.D. (2001). The formation of dimensionally ordered silicon nanowires within mesoporous silica. I Am. Chem. Soc., 123, 187-8.

Couchman, P.R. \& Jesser, W.A. (1977). Thermodynamic theory of size dependence of melting temperature in metals. Nature, 269, 481-3.

Cui, Y. \& Lieber, C.M. (2001). Functional nanoscale electronic devices assembled using silicon nanowire building blocks. Science, 291, 851-3.

Cui, Y.; Wei, Q.; Park, H. \& Lieber, C.M. (2001). Nanowire nanosensors for highly sensitive and selective detection of biological and chemical species. Science, 293 1289-92.

Cullis, A.G.; Canham, L.T.\& Calcott, P.D.J. (1997). The structural and luminescence properties of porous silicon. el Appl. Phys., 82, 909-65. 
Dai, J.Y.; Lauerhaas, J.M.; Setlur, A.A. \& Chang, R.P.H. (1996). Synthesis of carbonencapsulated nanowires using polycyclic aromatic hydrocarbon precursors. Chem. Phys. Lett., 258, 547-53.

Das, K.; Chakraborty, A.K.; NandaGoswami, M.L.; Shinga, R.K.; Dhar, A.; Coleman, K.S. \& Ray, S.K. (2007). Temperature dependent shape transformation of Ge nanostructures by the vapor-liquid-solid method. I Appl. Phys., 101, 074307.

Dujardin, E.; Ebbesen, T.W.; Hiura, H. \& Tanigaki, K. (1994). Capillarity and wetting of carbon nanotubes. Science, 265, 1850-2.

Erts, D.; Polyakov, B.; Daly, B.; Morris, M.A.; Ellingboe, S.; Boland, J. \& Holmes, J.D. (2006). High density germanium nanowire assemblies: contact challenges and electrical characterization". II Phys. Chem. B, 110, 820-6.

Gu, G.; Burghard, M.; Kim, G.T.; Dusberg, D.S.; Chiu, P.W.; Krstic, V.; Roth, S. \& Han, W.Q. (2001). Growth and electrical transport of germanium nanowires. I Appl. Phys., 90, 5747-51.

Hanrath, T. \& Korgel, B.A. (2002). Nucleation and growth of germanium nanowires seeded by organic monolayer-coated gold nanocrystals. I Am. Chem. Soc., 124, 14249.

Hanrath, T. \& Korgel, B.A. (2004). Chemical surface passivation of Ge nanowires. eI Am. Chem. Soc., 126, 15466-72.

Heath, J.R. \& LeGoues, F.K. (1993). A liquid solution synthesis of single crystal germanium quantum wires. Chem. Phys. Lett., 208, 263-8.

Huang, Y.; Duan, X.; Cui, Y.; Lauhon, L.J.; Kim, K. \& Lieber, C.M. (2001). Logic gates and computation from assembled nanowire building blocks. Science, 294, 1313.

Huang, Y.; Lin, J.; Zhang, J.; Ding, X.X.; Qi, S.R. \& Tang, C.C. (2005). A novel method for preparing carbon-coated germanium nanowires. Nanotech. 16, 1369-71.

Jin, C.-B.; Yang, J.-E. \& Jo, M.-H. (2006). Shape-controlled growth of single-crystalline Ge nanostructures. Appl. Phys. Lett., 88, 193105.

Kamins, T.I.; Williams, R.S.; Basile, D.P.; Hesjedal, T.; \& Harris, J.S. (2001). Ti-catalyzed Si nanowires by chemical vapor deposition: Microscopy and growth mechanisms. $\mathcal{I}$ Appl. Phys., 89, 1008-16.

Kamins, T.I.; Li X.; Williams, R.S. \& Liu, X. (2004). Growth and structure of chemically vapor deposited Ge nanowires on Si substrates. Nano. Lett., 4, 503-6.

Kang, K.; Gu, G.H.; Kim, D.A.; Park, C.G. \& Jo, M.-H. (2008). Self-organized growth of Ge nanowires from Ni-Cu bulk alloys. Chem. Mater., 20, 6577-9.

Kodambaka, S.; Tersoff, J.; Reuter, M.C. \& Ross, F.M. (2007). Germanium nanowire growth below the eutectic temperature. Science, 316, 729-32.

Lieber, C.M. (2003). Technical feature - nanoscale science and technology: building a big future from small things 2002 (MRS medalist presentation). MRS Bull., 28, 48691.

Loiseau, A.; Demoncy, N.; Stéphan, O.; Colliex, C. \& Pascard, H. (2000). Filling carbon nanotubes using an arc discharge. In: Tománek, D; Enbody, RJ, eds. Science and Application of Nanotubes, New York: Kluwer Academic/Plenum Publishers; pp. 116. 
Ma, D.D.D.; Lee, C.S.; Au, F.C.K.; Tong, S.Y. \& Lee, S.T. (2003). Small-diameter silicon nanowire surfaces. Science, 299 1874-7.

Maeda, Y.; Tsukamoto, N.; Yazawa, Y.; Kanemitsu, Y. \& Masumoto, Y. (1991). Visible photoluminescence of $\mathrm{Ge}$ microcrystals embedded in $\mathrm{SiO}_{2}$ glassy matrices. Appl. Phys. Lett., 59, 3168-70.

Mathur, S. \& Barth, S. (2008). One-dimensional semiconductor nanostructures: growth, characterization and device applications". Z. Phys. Chem., 222, 307-17.

Mathur, S.; Shen, H.; Sivakov, V. \& Werner, U. (2004). Germanium nanowires and core-shell nanostructures by chemical vapor deposition of $\left[\mathrm{Ge}\left(\mathrm{C}_{5} \mathrm{H}_{5}\right)_{2}\right]$. Chem. Mater., 16, 244956.

Miikin, L.I. (1961). Hand Book on X-ray Structural Analysis of Polycrystals, Uspenskii, Ya.-S. (Ed.), Fizmatgiz, Moscow.

Moffatt, W.G. (1976). The Handbook of binary phase diagrams, Genium, Schenectady, NY.

Morales, A.M. \& Lieber, C.M. (1998). A laser ablation method for the synthesis of crystalline semiconductor wires. Science, 279, 208-11.

Nguyen, P.; Ng, H.T. \& Meyyappan, M. (2005). Growth of individual vertical germanium nanowires. Adv. Mater., 17, 549-53.

Omi, H. \& Ogino, T. (1997). Self-assembled Ge nanowires grown on Si(113). Appl. Phys. Lett., 71, 2163-5.

Önce, C. \& Yürüm, Y. (2006). Carbon nanotube synthesis via the catalytic CVD method: a review on the effect of reaction parameters. Fullerenes, Nanotubes, and Carbon Nanostructures, 14, 17-37, and references therein.

Pandurangan, A.; Morin, C.; Qian, D.; Andrews, R. \& Crocker, M. (2009). Single-step synthesis of germanium nanowires encapsulated within multi-walled carbon nanotubes. Carbon, 47, 1708-14.

Park, Y.D.; Hanbicki, A.T.; Erwin, S.C.; Hellberg, C.S.; Sullivan, J.M.; Mattson, J.E.; Ambrose T.F.; Wilson, A.; Spanos, G.; Jonker, B.T. (2002). A group-IV ferromagnetic semiconductor: $\mathrm{Mn}_{\mathrm{x}} \mathrm{Ge}_{1-\mathrm{x}}$. Science, 295, 651-654.

Pokropivnyi, V.V. (2001). Non-carbon nanotubes (review). II. Types and structure. Powder Met. and Met. Ceramics, 40, 582-94.

Polyakov, B.; Daly, B.; Prikulis, J.; Lisauskas, V.; Vengalis, B.; Morris, M.A.; Holmes, J.D. \& Erts, D. (2006). High-density arrays of germanium nanowire photoresistors". Adv. Mater, 18, 1812-6.

Qian, D.; Andrews, R.; Jacques, D.; Kichambare, P.; Lian, G. \& Dickey, E. C. (2003). Lowtemperature synthesis of large-area CNx nanotube arrays. I Nanosci. Nanotech. 3, 93-7.

Rajaputra, S.; Mangu, R.; Clore, P.; Qian, D.; Andrews, R. \& Singh, V.P. (2008). Multiwalled carbon nanotube arrays for gas sensing applications. Nanotechnology, 19, 345502.

Ryan K.M.; Erts D.; Olin H.; Morris M.A. \& Holmes J.D. (2003). Three dimensional architectures of ultra-high density semiconducting nanowires deposited on chip. $I$ Am. Chem. Soc., 125, 6284-8.

Singh, A.K.; Kumar, V. \& Kawazoe, Y. (2004). Ferromagnetism and piezomagnetic behavior in Mn-doped germanium nanotubes. Phy. Rev. B., 69, 233406, 1-4. 
Song, H.J.; Yoon, H.J.; Shin, H.-J.; Lim, H.; Park, C. \& Choi, H.C. (2009). Growth of germanium nanowires using liquid $\mathrm{GeCl}_{4}$ as a precursor: the critical role of $\mathrm{Si}$ impurities. Chem. Commun., 2009, 5124-6.

Sun, X.H.; Didychuk, C.; Sham, T.K. \& Wong, N.B. (2006). Germanium nanowires: synthesis, morphology and local structure studies. Nanotechnology, 17, 2925-30.

Sun, X.H.; Tang, Y.H.; Zhang, P.; Naftel, S.; Sammynaiken, R.; Sham, T.K.; Zhang, Y.F.; Peng, H.Y.; Wong, N.B. \& Lee, S.T. (2001). X-ray absorption fine structure and electron energy loss spectroscopy study of silicon nanowires at the SiL3,2 edge. $I$ Appl. Phys., 90, 6379-83.

Sun, X.H.; Wang, S.D.; Wong, N.B.; Ma, D.D.D.; Lee, S.T. \& Teo, B.K. (2003). FTIR spectroscopic studies of the stabilities and reactivities of hydrogen-terminated surfaces of silicon nanowires. Inorg. Chem., 42 2398-404.

Sutter, E.; Ozturk, B. \& Sutter, P. (2008) Selective growth of Ge nanowires by lowtemperature thermal evaporation. Nanotechnology, 19, 435607.

Sutter, E. \& Sutter, P. (2006). Au-induced encapsulation of Ge nanowires in protective C shells. Adv. Mater., 18, 2583-8.

Sze, S.M. (1981). Physics of semiconductor devices , Wiley, New York.

Takagi, D.; Hibino, H.; Suzuki, S.; Kobayashi, Y. \& Homma, Y. (2007). Carbon nanotube growth from semiconductor particles. Nano Lett., 7, 2272-5.

Wagner, R.S. \& Ellis, W.C. (1964). Vapour-liquid-solid (VLS) mechanism of single crystal growth. Appl. Phys. Lett., 4, 89-90.

Wang, D. \& Dai, H. (2002). Low-temperature synthesis of single-crystal germanium nanowires by chemical vapor deposition. Angew. Chem. Int. Ed., 41, 4783-6.

Wang, D. \& Dai, H. (2006). Germanium nanowires: from synthesis, surface chemistry, and assembly to devices. Appl. Phys. A, 85, 217-25.

Wang, D., Chang, Y.-L., Liu, Z. \& Dai, H. (2005). Oxidation resistant germanium nanowires: bulk synthesis, long chain alkanethiol functionalization, and Langmuir-Blodgett assembly. I Am. Chem. Soc., 127, 11871-5.

Wang, Y.; Schmidt, V.; Senz, S. \& Gösele, U. (2006). Epitaxial growth of silicon nanowires using an aluminium catalyst. Nature Nanotechnol., 1, 186-9.

Wu, Y. \& Yang, P. (2000). Germanium nanowire growth via simple vapor transport. Chem. Mater., 12, 605-7.

Wu, Y. \& Yang, P. (2000). Germanium/carbon core-sheath nanostructures. Appl. Phys. Lett., $77,43-5$

Yao, Y. \& Fan, S. (2007). Si nanowires synthesized with Cu catalyst. Mater. Lett., 61, 177-81.

Yin, L.-W.; Li, M.-S.; Bando, Y.; Golberg, D.; Yuan, X. \& Sekiguchi, T. (2007). Tailoring the optical properties of epitaxially grown biaxial $\mathrm{ZnO} / \mathrm{Ge}$, and coaxial $\mathrm{ZnO} / \mathrm{Ge} / \mathrm{ZnO}$ and Ge/ZnO/Ge heterostructures. Adv. Funct. Mater., 17, 270-6.

Zhang, X.Q.; Li, H. \& Liew, K.M. (2007). The structures and electrical transport properties of germanium nanowires encapsulated in carbon nanotubes. I Appl. Phys., 102, 073709.

Zhang, Y.F.; Tang, Y.H.; Wang, N.; Lee, C.S.; Bello, I. \& Lee, S.T. (2000). Germanium nanowires sheathed with an oxide layer. Phys. Rev. B, 61, 4518-21. 
Zhang, Y.; Suenaga, K.; Colliex, C. \& Iijima, S. (1998). Coaxial nanocable: silicon carbide and silicon oxide sheated with boron nitride and carbide. Science, 281, 973-5.

Ziegler, K.J.; Polyakov, B.; Kulkarni, J.S.; Crowley, T.A.; Ryan, K.M.; Morris, M.A.; Erts, D. \& Holmes, J.D. (2004). Conductive films of ordered nanowire arrays. I Mater. Chem., 14, 585-9. 


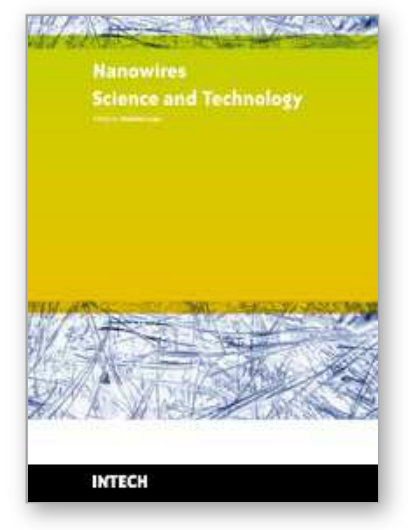

\author{
Nanowires Science and Technology \\ Edited by Nicoleta Lupu
}

ISBN 978-953-7619-89-3

Hard cover, 402 pages

Publisher InTech

Published online 01, February, 2010

Published in print edition February, 2010

This book describes nanowires fabrication and their potential applications, both as standing alone or complementing carbon nanotubes and polymers. Understanding the design and working principles of nanowires described here, requires a multidisciplinary background of physics, chemistry, materials science, electrical and optoelectronics engineering, bioengineering, etc. This book is organized in eighteen chapters. In the first chapters, some considerations concerning the preparation of metallic and semiconductor nanowires are presented. Then, combinations of nanowires and carbon nanotubes are described and their properties connected with possible applications. After that, some polymer nanowires single or complementing metallic nanowires are reported. A new family of nanowires, the photoferroelectric ones, is presented in connection with their possible applications in non-volatile memory devices. Finally, some applications of nanowires in Magnetic Resonance Imaging, photoluminescence, light sensing and field-effect transistors are described. The book offers new insights, solutions and ideas for the design of efficient nanowires and applications. While not pretending to be comprehensive, its wide coverage might be appropriate not only for researchers but also for experienced technical professionals.

\title{
How to reference
}

In order to correctly reference this scholarly work, feel free to copy and paste the following:

Dali Qian, Mark Crocker, A. Pandurangan, Cedric Morin and Rodney Andrews (2010). Synthesis of Germanium/Multi-Walled Carbon Nanotube Core-Sheath Structures via Chemical Vapor Deposition, Nanowires Science and Technology, Nicoleta Lupu (Ed.), ISBN: 978-953-7619-89-3, InTech, Available from: http://www.intechopen.com/books/nanowires-science-and-technology/synthesis-of-germanium-multi-walledcarbon-nanotube-core-sheath-structures-via-chemical-vapor-deposi

\section{INTECH}

open science | open minds

\author{
InTech Europe \\ University Campus STeP Ri \\ Slavka Krautzeka 83/A \\ 51000 Rijeka, Croatia \\ Phone: +385 (51) 770447 \\ Fax: +385 (51) 686166 \\ www.intechopen.com
}

\author{
InTech China \\ Unit 405, Office Block, Hotel Equatorial Shanghai \\ No.65, Yan An Road (West), Shanghai, 200040, China \\ 中国上海市延安西路65号上海国际贵都大饭店办公楼 405 单元 \\ Phone: +86-21-62489820 \\ Fax: +86-21-62489821
}


(C) 2010 The Author(s). Licensee IntechOpen. This chapter is distributed under the terms of the Creative Commons Attribution-NonCommercialShareAlike-3.0 License, which permits use, distribution and reproduction for non-commercial purposes, provided the original is properly cited and derivative works building on this content are distributed under the same license. 